\title{
Review Article \\ Epigenetic Regulations in Neural Stem Cells and Neurological Diseases
}

\author{
Hang Zhou, ${ }^{1,2}$ Bin Wang, ${ }^{2}$ Hao Sun, ${ }^{3}$ Xingshun $X u \mathbb{D}^{1,2}$ and Yongxiang Wang $\mathbb{D}^{3}$ \\ ${ }^{1}$ Department of Neurology, The Second Affiliated Hospital of Soochow University, Suzhou, China \\ ${ }^{2}$ Institute of Neuroscience, Soochow University, Suzhou, China \\ ${ }^{3}$ Department of Orthopedics, Clinical Medical School, Yangzhou University, Northern Jiangsu People's Hospital, \\ Yangzhou 225001, China
}

Correspondence should be addressed to Xingshun Xu; xingshunxu@suda.edu.cn and Yongxiang Wang; wyx918spine@163.com Received 4 November 2017; Accepted 8 January 2018; Published 18 March 2018

Academic Editor: Yujing Li

Copyright (c) 2018 Hang Zhou et al. This is an open access article distributed under the Creative Commons Attribution License, which permits unrestricted use, distribution, and reproduction in any medium, provided the original work is properly cited.

\begin{abstract}
Among the regulatory mechanisms of the renewal and differentiation of neural stem cells, recent evidences support that epigenetic modifications such as DNA methylation, histone modification, and noncoding RNAs play critical roles in the regulation on the proliferation and differentiation of neural stem cells. In this review, we discussed recent advances of DNA modifications on the regulative mechanisms of neural stem cells. Among these epigenetic modifications, DNA 5-hydroxymethylcytosine (5hmC) modification is emerging as an important modulator on the proliferation and differentiation of neural stem cells. At the same time, Ten-eleven translocation (Tet) methylcytosine dioxygenases, the rate-limiting enzyme for the 5-hydroxymethylation reaction from 5-methylcytosine to 5-hydroxymethylcytosine, play a critical role in the tumorigenesis and the proliferation and differentiation of stem cells. The functions of $5 \mathrm{hmC}$ and TET proteins on neural stem cells and their roles in neurological diseases are discussed.
\end{abstract}

\section{Introduction}

Human beings are developed from a fertilized egg into a complete individual; during the whole process, a series of precise regulations on the development are included, such as gene expression and gene silence [1], transcriptional regulation [2], posttranscriptional regulation [3], hormone regulation [4], chromosome behavior regulation [5], and apoptosis [6]. For these different regulative pathways, their target cells are embryonic stem cells (ESCs). ESCs are totipotent stem cells that had a capability to proliferate and differentiate into appropriate lineages to form specialized cells and organs and play a central role in the developmental process [7]. Due to the powerful plasticity and potential of ESCs as a high potential cell replacement therapy for many diseases, stem cells are considered to have an appreciable translational prospect in the field of regenerative medicine [8]. Except for ESCs at the embryonic stage of the development, adult stem cells (ASCs) exist in different tissues at the adult stage of the development [9]. ASCs are often in a resting state in individuals and exhibit different potentials of regeneration and differentiation under pathological conditions or special incentives. Reynolds and Weiss first found that the neurons isolated from the striatum of the adult mouse brain could proliferate and differentiate in vitro with epidermal growth factors [9], indicating the existence of neural stem cells (NSCs) in the mature nervous system. They also demonstrated that NSC has the ability to self-renew and differentiate into other types of cells like neurons, astrocytes, and oligodendrocytes under many conditions such as growth factors, neurotransmitters, hormones, injury, or environmental factors [9]. However, the renewal and differentiation ability of NSC is limited; in the process of aging or pathological conditions, neuronal cell loss is much more than newly generated neurons and glial cells from NSCs, resulting in different neurological disorders including Alzheimer's disease [10], Parkinson's disease [11], Huntington's disease [12], neuroendocrine tumors [13], and ataxia [14]. Therefore, the regulation on the renewal and differentiation of NSCs or NSC transplantation therapy are considered an important 
therapeutic strategy for the treatment of these neurodegenerative diseases.

Among the regulatory mechanisms of the renewal and differentiation of NSCs, epigenetic modification plays a critical role in monitoring the phase transition during individual development, maintaining the directional differentiation of stem cells, regulating the proliferation of specific cells, and controlling the process of differentiation $[15,16]$. For example, in the process of umbilical cord mesenchymal stem cells (UMSCs) being differentiated to neural stem-like cells (uNSCLs), E1A-like inhibitor of differentiation 3 (EID3), an important member of EID gene family that has the main function of p300/CBP inhibitors (a transcriptional coactivator) in response to cell transformation, growth arrest, or cell apoptosis, directly interacts with DNMT3A, a DNA methyltransferase (DNMT) for DNA methylation, suggesting that DNA methylation may be involved the regulation of transdifferentiating from UMSCs to uNSCLs as a key mechanism in epigenetic regulation of stem cell reprogramming [17]. So far, epigenetic modification is a hot topic in recent years. Except for DNA methylation, histone modification, micro-RNA, chromatin remodeling, and other epigenetic modification are found to play important roles in the regulation of stem cells [18]. In this article, we will review the recent advances of different epigenetic modifications on NSCs, but mainly focus on the role of $5 \mathrm{hmC}$ as a new player in the regulation of the renewal and differentiation of ESCs or NSCs.

\section{Recent Advances on Epigenetic Regulation on Stem Cells}

It is strongly believed that the basis of cell differentiation in ontogeny is based on the regulation of intracellular factors, while environmental factors also play a role as a main cause [19]. Epigenetic modifications including methylation, acetylation, ubiquitination, and phosphorylation on DNA, RNA, or proteins mediate the interaction between the environment and the organism [20]. Interestingly, recent evidences demonstrate that epigenetic modification changes can be inherited to the next generation [21]. Here, we present a brief overview of current advances on epigenetic modifications and NSCs.

2.1. DNA Methylation. The increasing evidences demonstrate that DNA methylation is involved in the proliferation and differentiation of stem cells [22]. DNA methylation prevents transcriptional factors from binding to promoters, such as Oct4 and Nanog, thereby limiting gene expression [23]. The process of DNA methylation is catalyzed by DNA methyltransferase, mainly DNMT1, DNMT3A, and DNMT3B. DNMT3 enzyme is a de novo methyltransferase [24] and DNMT1 is mainly involved in the maintaining of DNA methylation in dividing somatic cells [25]. The deletion of DNMT3A in hematopoietic stem cells impaired the differentiation of transplanted hematopoietic stem cells and increased the level of hematopoietic stem cells in the bone marrow [22]. In skeletal muscle stem cells, the DNA methylation of $\mathrm{CpG}$ dinucleotide in the promoter or enhancer region reduces gene expression of $\operatorname{Pax} 7$ and MyoD [26].
Similarly, Uhrf1 (ubiquitin-like PHD ring finger-1; also known as Np95) mainly interacts with DNMT1 to maintain DNA methylation in NSCs; the deletion of Uhrf1 in NSCs leads to increase the global DNA methylation and delayed neurodegeneration [27]. Recent evidences showed that Methyl CpG binding domain protein 1 (MBD1) is expressed in neural stem cells (aNSCs) of dentate gyrus of the adult hippocampus and maintains the integrity and stemness of NSC by inhibiting differentiation [28]. MBD1 and Methyl CpG binding protein 2 (Mecp2) belong to the methyl-CpGbinding protein family and play a key role to link DNA methylation and transcriptional regulation on differentiation genes [29]. MBD1 deficiency leads to the accumulation of undifferentiated NSCs and impaired transition into the neuronal lineage [28]. DNA methylation is closely related to stem cell-related diseases. A recent study found that there are a large number of gene mutations of DNMT3A in acute myeloid leukemia which is a malignant tumor characterized by clonal stem cell proliferation and aberrant block in differentiation [30]. Fetal alcohol syndrome showed that alcohol exposure to cultured NSCs altered normal DNA methylation programming of key neural stem cell genes and retarded NSC migration and differentiation [31], supporting the role of aberrant patterns of DNA methylation in fetal neural development after embryonic alcohol exposure.

2.2. Histone Modification. Histone modification refers to the process of histone methylation, acetylation, phosphorylation, polyadenylation, ubiquitination, and ADP glycosylation under the action of related enzymes. Histone-mediated epigenetic gene silencing is to remove acetyl groups from histone tails catalyzed by histone deacetylase (HDAC) enzymes and enhance the binding of histones to DNA and the aggregation of chromosomes, preventing transcription factors into the regulatory region [32]. HDAC1 is highly expressed in the oligodendrocyte differentiation period of the corpus callosum; HDAC inhibitors blocked oligodendrocyte differentiation and cause demyelination in the corpus callosum of postnatal rats [33]. The recent study indicated that the Arf-p53 axis also might be involved in the regulation of histone acetylation on the proliferation and senescence of the neurospheres [34].

Histone demethylation is also an important histone modification. It has two families, LSD1 (Lysine-specific demethylase 1) and JmjC (a domain), to regulate the proliferation and differentiation of stem cells. Inhibiting the activity of LSD1 or knockdown of LSD1 expression leads to the decreased proliferation of neural stem cells [35]. In addition, LSD1 plays a crucial role in maintaining the silencing of several developmental genes in human embryonic stem cells by regulating the balance between $\mathrm{H} 3 \mathrm{~K} 4$ (lysine 4 on histone $\mathrm{H} 3$ protein) and $\mathrm{H} 3 \mathrm{~K} 27$ methylation in its regulatory region [36]. Thus, histone modifications play a role in inducing NSC differentiation into neurons and glial lineages, but the mechanisms are still not clear.

2.3. Noncoding RNA. Noncoding RNAs (ncRNAs) are a class of RNA molecules that have no ability to translate into proteins but function as regulatory factors at transcriptional or 
posttranscriptional levels, including ribosomal RNAs (rRNAs), microRNAs (miRNAs), piwi-interacting RNAs (piRNAs), long noncoding RNAs (lncRNAs), and others [37]. These ncRNAs have shown to play distinct but also conserved roles in regulation of differentiation of NSCs [38-40]. Among different ncRNAs, current evidences demonstrate that miRNAs play critical roles in the regulation of differentiation of NSCs. miRNAs are a group of small RNA molecules of 20-24 nucleotides widely found in eukaryotes. They bind to target mRNAs to regulate their gene expression by promoting the degradation of target mRNAs. Similarly, microRNA is also involved in the regulation of NSC differentiation and proliferation dynamic homeostasis; for example, high levels of miR-184, which are inhibited by methyl-CpG binding protein 1, promote stem cell proliferation but inhibit adult neural stem/progenitor cell (aNSCs) differentiation [41]. MiR-145 directly regulates Nurr1 (a nuclear receptor) expression level, and overexpression of miR-145 inhibits the differentiation effect of BMP2; knockdown of miR-145 promoted the upregulation of Nurrl, resulting in the differentiation of NSCs into dopaminergic neurons [42]. MicroRNA can regulate many factors such as CT4, SOX2, and KLF4 in embryonic stem cells that are the direct targets of miR-145. The deletion of miR-145 increases the expression of OCT4, SOX2, and KLF4 and further inhibits the differentiation of NSC [43]. Recent studies showed that aging process begin when hypothalamic stem cells that coexpress Sox 2 and Bmil are ablated accompanying with substantial loss of hypothalamic cells; the injection of exosomal miRNA in the cerebrospinal fluid, greatly prevented the cell aging process [44]. Therefore, more and more evidences showed that ncRNAs like miRNA are involved in the regulation of differentiation of NSCs.

\section{Ten-Eleven Translocation (Tet) Proteins- 5hmC Modification-Related Enzymes}

Tet family proteins are a group of $\alpha$-ketoglutarate $(\alpha-\mathrm{KG})$ and $\mathrm{Fe} 2+-$ dependent monooxygenase to catalyze the conversion of $5 \mathrm{mC}$ to $5 \mathrm{hmC}$, concluding Tet1, Tet2, and Tet2 [45]. In 2009, Tahiliani et al. found that Tet1 catalyzes the reaction of $5 \mathrm{mC}$ to $5 \mathrm{hmC}$ [46]; thereafter, Tet 2 and Tet 3 have been found to have similar catalytic activity [47]. Although the main functions of the three enzymes are to oxidize $5 \mathrm{mC}$ to $5 \mathrm{hmC}$, the distribution of the enzymes is different. The expression of Tet1 protein in embryonic stem cells and nervous system is high [48-50]; Tet2 is widely distributed and relatively high in hematopoietic system; Tet3 is mainly expressed in colon, muscle tissues, and less in brain tissues [51]. The three Tet enzymes contain a structurally similar carboxyl terminal catalytic region, which catalyzes the synthesis of $5 \mathrm{hmC}$ activity [45]. The catalytic domain of Tet proteins has 3 metal ion ( $\mathrm{Fe} 2+$ ) and $\alpha$-KG binding site to enhance its catalytic activity [46]. Tet1 and Tet3 have an amino terminal CXXC zinc finger protein domain, whereas Tet2 lacks this structure and needs to be assisted by IDAX protein with similar functions [52]. The CXXC domain protein of Tet2 is encoded by a distinct gene IDAX. The IDAX CXXC domain binds DNA sequences containing unmethylated $\mathrm{CpG}$ dinucleotides, localizes to promoters and $\mathrm{CpG}$ islands in genomic DNA, and interacts directly with the catalytic domain of Tet2 [52]. IDAX (also known as CXXC4), a reported inhibitor of Wnt signaling, regulates Tet2 protein expression [53]. Unexpectedly, IDAX expression results in caspase activation and Tet2 protein downregulation in a manner that depends on DNA binding through the IDAX CXXC domain, suggesting that IDAX recruits Tet2 to DNA before degradation [52]. Notably, the IDAXrelated protein CXXC5 resembles IDAX in inhibiting Wnt signaling [54]. Therefore, the distribution and structure of Tet enzymes determine the distribution of $5 \mathrm{hmC}$ modifications in brain and their different roles in different diseases. Tet1 knockout mice showed impaired hippocampal neurogenesis resulting in learning and memory deficiency [55]. Tet2 functional disruption or knockout influences hematopoietic cell homeostasis and hematopoietic differentiation and promotes the development of myeloid malignancies [56]. Although either Tet 1 or tet 2 knockout mice are viable and fertile, Tet3 knockout mice are perinatally lethal [51]. These demonstrate the different roles of Tet proteins in the different tissues and in the devolvement of different organs. The functions of Tet proteins and its related phenotypes in rodent animals and diseases in human are summarized in Table 1.

5-Hydroxymethylcytosine ( $5 \mathrm{hmC}$ ), the oxidative product of $5 \mathrm{mC}$, was found in mammals with surprisingly high abundance in 2009 [46, 57]. Recent studies showed that $5 \mathrm{mC}$ is not the final chemical steps for gene silencing; Tet proteinassociated DNA demethylation can transform 5-methyl cytosine $(5 \mathrm{mC})$ into 5-hydroxymethycytosine $(5 \mathrm{hmC})$, 5formylcytosine $(5 \mathrm{fC})$, and 5 -carbosycytosine $(5 \mathrm{caC})$, but $5 \mathrm{fC}$ and $5 \mathrm{caC}$ is much less than 5-hydroxymethylcytosine $[58,59]$. Interestingly, for individual tissues, the levels of $5 \mathrm{hmC}, 5 \mathrm{fC}$, and $5 \mathrm{caC}$ were not significantly related; for example, although $5 \mathrm{hmC}$ is more abundant in mouse brains than in ESCs, the levels of $5 \mathrm{fC}$ and $5 \mathrm{caC}$ are less abundant [45]. $5 \mathrm{fC}$ and $5 \mathrm{caC}$ can be further removed by the base excision repair (BER) pathway and thymine-DNA glycosylase [60]. This pattern suggests that the different steps of demethylation cycle are different in different tissues [61]. In addition, Tet protein overexpression or depletion can increase or decrease the content of $5 \mathrm{hmC}, 5 \mathrm{fC}$, and $5 \mathrm{caC}$ in the genome [61]. The discovery of Tet proteins speeds the exploration of the functions of $5 \mathrm{hmC}[46,57]$. Because of its important functions, $5 \mathrm{hmC}$ in DNA has been considered as the sixth base. More evidences show that demethylation by $5 \mathrm{hmC}$ regulates the proliferation of NSCs and neurogenesis [27]. Therefore, we further discuss the regulation of $5 \mathrm{hmC}$ on NSCs and related neurological diseases.

\section{Tet Proteins and DNA $5 \mathrm{hmC}$ Modifications Are Involved in the Regulation on the Proliferation and Differentiation of NSCs}

The direction of cell differentiation is determined by the specific expression of tissue-specific genes, while DNA $5 \mathrm{mC}$ is involved in the regulation of gene expression and 
TABLE 1: Tet proteins and their functions.

\begin{tabular}{|c|c|c|c|c|}
\hline Genes & Distribution & Structure & $\begin{array}{l}\text { Functions of Tet enzymes } \\
\text { Knockout phenotypes in rodents }\end{array}$ & Related diseases in humans \\
\hline Tet1 & $\begin{array}{l}\text { Mainly in ESCs and } \\
\text { nervous system [48]. }\end{array}$ & $\begin{array}{l}\text { Contains CXXC, } \\
\text { Cys-rich, and DSBH } \\
\text { domains }\end{array}$ & $\begin{array}{l}\text { (1) Abnormal hippocampal neurogenesis, } \\
\text { with learning and memory fading [55]. } \\
\text { (2) Antidepressive phenotypes [94] } \\
\text { (3) Skews differentiation towards } \\
\text { extraembryonic lineages in the } \\
\text { teratoma [99]. }\end{array}$ & $\begin{array}{l}\text { (1) Acute leukemia [100]. } \\
\text { (2) Gastric cancer }([101,102] \text {, } \\
\text { Deng, [103]). } \\
\text { (3) Breast cancer [104]. }\end{array}$ \\
\hline Tet2 & $\begin{array}{l}\text { Widely distributed and } \\
\text { high in hematopoietic } \\
\text { system [48]. }\end{array}$ & $\begin{array}{l}\text { Contains Cys-rich } \\
\text { and DSBH domains } \\
\text { without CXXC domain }\end{array}$ & $\begin{array}{l}\text { (1) Hematopoietic cell homeostasis and } \\
\text { hematopoietic differentiation } \\
\text { impairment, myeloid malignancies [56]. } \\
\text { (2) Retinal neurons developmental failure } \\
\text { in zebrafish [105]. }\end{array}$ & $\begin{array}{l}\text { (1) Polycythemia vera [106, 107]. } \\
\text { (2) Primary myelofibrosis [107]. } \\
\text { (3) Myelodysplastic syndrome } \\
\text { [106]. } \\
\text { (4) Myeloproliferative neoplasm } \\
\text { [108]. } \\
\text { (5) Melanoma [109]. }\end{array}$ \\
\hline \multirow[t]{4}{*}{ Tet3 } & $\begin{array}{l}\text { Mainly in colon and } \\
\text { muscle tissues, less in } \\
\text { brain tissue [51]. }\end{array}$ & $\begin{array}{l}\text { Contains CXXC, } \\
\text { Cys-rich, and DSBH } \\
\text { domains }\end{array}$ & $\begin{array}{l}\text { (1) Developmental failure [72] and } \\
\text { embryonic sublethality [110]. } \\
\text { (2) Impaired differentiation and increased } \\
\text { apoptosis [72]. } \\
\text { (3) Fear extinction impairments in mice } \\
\text { [111]. } \\
\text { (4) Abnormal morphogenesis of retinal } \\
\text { neurons in zebrafish [105]. } \\
\text { (5) Abnormal neural differentiation and } \\
\text { skewed toward cardiac mesodermal } \\
\text { fate in mouse ESC [112]. }\end{array}$ & NA \\
\hline & \multicolumn{2}{|c|}{ Tet1/2 DKO } & $\begin{array}{l}\text { Embryonic stage death and little normal } \\
\text { growth [113] }\end{array}$ & NA \\
\hline & \multicolumn{2}{|c|}{ Tet1/3 DKO } & $\begin{array}{l}\text { (1) Dendritic arborization inhibition in } \\
\text { mice [114] } \\
\text { (2) Holoprosencephaly [115]. }\end{array}$ & NA \\
\hline & \multicolumn{2}{|c|}{ Tet1/2/3 TKO } & Developmental disorders [116] & NA \\
\hline
\end{tabular}

CXXC: Cys-X-X-Cys domain; DSBH: double-stranded beta helix; DKO: double knockout; ESCs: embryonic stem cells; TKO: triple knockout; NA: not available.

differentiation of cells in a specific direction [62-64]. Previous studies have shown that about $1.4 \%$ of $\mathrm{CpG}$ islands undergo a significant remethylation process during the differentiation of embryonic stem cells into NSCs and NPCs [65]. The increasing line of evidences indicate that $5 \mathrm{mC}$ directly inhibits transcription factors to bind to DNA [23] or recruits MeCP2 and MBD to form a complex and further prevent gene transcriptions that relate to the differentiation of NSCs [66]. Therefore, DNA methylation plays an important role in neural cell differentiation. Apparently, as an important demethylation mechanism, DNA $5 \mathrm{hmC}$ modification and Tet enzymes can be involved in the regulations of NSCs in theory.

Recently, $5 \mathrm{hmC}$ has been found in the mammalian genome and has been shown to be about 10 times more abundant in neurons than in some peripheral nervous tissues [67]. This suggests that $5 \mathrm{hmC}$ may be a stable epigenetic marker involved in cell specific mechanisms to achieve its function in the brain. More and more evidences demonstrated that Tet enzymes and Tet-mediated $5 \mathrm{hmC}$ modifications are involved in the proliferation and differentiation of ESCs and NSCs $[29,58,68,69]$. Hahn et al. found that the increase of $5 \mathrm{hmC}$ modification in gene bodies is associated with genes important for neuronal functions during neuronal differentiation in mouse brain regions; however, gene activation for neuronal differentiation is not related to substantial DNA demethylation [69]. At the same time, overexpression of Tet 2 and Tet 3 also promotes the progression of neuronal differentiation [69]. Similarly, in Sirt6-knockout ESCs, the expression of Oct4, Sox2, and Nanog (the downstream of Sirt6) is inhibited and the upregulation of Tet enzymes and the significant increase of DNA $5 \mathrm{hmC}$ are found, resulting in ESC skewed development towards neuroectoderm [68]. This suggests that Sirt6-regulated ESC differentiation is in a Tet enzyme and 5hmC-dependent manner [68], supporting Hahn et al.'s results. A recent study further demonstrates that $5 \mathrm{hmC}$ dynamics is correlated with the differentiation of aNSCs; however, Tet 2 primarily contributes to $5 \mathrm{hmC}$ acquisition during the differentiation of aNSCs [58]. Therefore, these evidences support the critical role of $5 \mathrm{hmC}$ modifications in the differentiation of NSCs.

Tet proteins, as the important enzymes for the conversion of $5 \mathrm{mC}$ to $5 \mathrm{hmC}$, also showed their functions on the proliferation/differentiation of NSCs. Tet1 depletion impairs hippocampal neurogenesis accompanied with poor learning and memory in mice; at the same time, Tetl deficiency results in reduced neural progenitor pool in adult subgranular zone [55]. These results provided in vivo evidences that 
Tet1 deficiency in the central nervous system decrease the proliferation of adult NSCs in the hippocampal dentate gyrus. Moran-Crusio et al. showed that the depletion of Tet2 stimulates aNSCs proliferation but impairs the differentiation of aNSCs [56]. Tet2 interacted with the neuronal transcription activator Foxo3a, a member of the helix-turnhelix-like family proteins [70], and coregulated key genes involved in aNSC differentiation [58]. Moreover, Tet3 plays critical roles in neural progenitor cell maintenance [71] but is not required for NSC fate [72]. However, how Tet proteins interact with cofactors to regulate target genes responsible for the proliferation and differentiation of NSCs remains unclear. The possible regulative mechanisms are proposed in Figure 1.

\section{Abnormal 5hmC and Neurological Diseases}

The growing evidences demonstrate that $5 \mathrm{hmC}$ has high abundance in the brain and play a critical role to in the maintenance of normal neurodevelopment and functions of central nervous system. Thus, accumulating evidences showed that abnormal $5 \mathrm{hmC}$ modifications are involved the pathophysiology of different neurological diseases.

5.1. Alzheimer's Disease (AD). Alzheimer's disease (AD) is one of the most common age-related neurodegenerative disorders in the central nervous system, characterized by progressive cognitive decline and loss of neuronal cells [73]. The pathogenesis of $\mathrm{AD}$ has yet to be defined, but there are evidences to support its genetic abnormalities, such as the mutations in $\beta$-amyloid precursor gene and presenilin $1 / 2$. Previous study has shown that AD is associated with DNA methylation [74]. It has been found that levels of $5 \mathrm{mC}$ and DNMT in neurons are reduced in patients with $\mathrm{AD}$ [74]. At the same time, $5 \mathrm{hmC}$ level was reported to decrease in the hippocampal tissue of patients with $\mathrm{AD}$ [75]. However, a study has shown that brain $5 \mathrm{mC}$ and $5 \mathrm{hmC}$ levels increased in patients with $\mathrm{AD}$ [76]. The reasons for this inconsistency need to be further investigated. In APP-presenilin1 double transgenic mice, $5 \mathrm{hmC}$ abundance in different brain regions showed differential response to the pathogenesis [77]. Further gene ontology analyses indicated that differential hydroxymethylation region- (DhMR-) associated genes are highly enriched in multiple signaling pathways involving neuronal development/differentiation [77], suggesting that DNA $5 \mathrm{hmC}$ modification is an epigenetic modifier on neurogenesis or NSC differentiation in aging or AD [78]. Interestingly, Tet1 is found to decrease in the hippocampus of patients with $\mathrm{AD}$ [79]. Tet1 knockout mice show impaired hippocampal neurogenesis as well as learning and memory defects $[55,80]$. Therefore, Tet1 functions as a critical enzyme to regulate $5 \mathrm{hmC}$ modifications on those genes related to the proliferation and differentiation of NSCs and further promotes neurogenesis in adult brains.

5.2. Huntington's Disease (HD). HD is an autosomal dominant disorder characterized by chorea, dystonia, slow and unexpected decline in cognitive function, and mental disorders [81]. At present, Huntington gene exon CAG repeats are considered as the major cause that leads to abnormal accumulation of the first amino acid polyglutamine in huntingtin proteins. Despite extensive research, the pathogenesis of neurodegeneration in $\mathrm{HD}$ is still unknown. ADORA2A gene encodes an adenylate A2A receptor, a G proteincoupled receptor that is highly expressed in the normal basal ganglia and is severely reduced in HD [82]. Recent studies have shown that HD results in an increase of $5 \mathrm{mC}$ expression and a decrease of $5 \mathrm{hmC}$ expression at the $5^{\prime}$-UTR end of the ADORA2A gene compared with the same age group [83]. Except for the decreased of ADORA2A gene $5 \mathrm{hmC}$ modification, a significant decrease of global $5 \mathrm{hmC}$ modification is found in $\mathrm{HD}$ mice with $128 \mathrm{CAG}$ repeats, indicating the involvement of $5 \mathrm{hmC}$ in the pathogenesis of $\mathrm{HD}$ and a novel epigenetic marker in HD [82]. Further $5 \mathrm{hmC}$ profiling analysis indicates that most genes with differentially hydroxymethylated regions are highly related to the pathological changes in $\mathrm{HD}$, suggesting that gene $5 \mathrm{hmC}$ modifications are involved in the regulation of neurogenesis, neuronal function, and survival in HD brain [82]. Because previous studies have shown the abnormal neurogenesis in HD [84], aberrant epigenetic regulation on relevant genes may impair the neurogenesis in brains with HD. Recent study demonstrated that targeting histone modification to downregulate the key genes for the pathology of HD causes beneficial effects in a Drosophila model of HD [85]. Therefore, the modulation of $5 \mathrm{hmC}$ signature in HD may be an effective strategy to ameliorate the symptoms of HD.

5.3. Rett Syndrome. Rett syndrome is considered as an inherited disease characterized by progressive mental decline, autistic behavior, ataxia, and anxiety in the early life of those who suffer from the disease. The etiology and genetic pattern of this disease remain unknown. The primary cause of Rett syndrome is caused by methyl CpG binding protein 2 (MeCP2) gene mutations that result in loss of function of MeCP2 [86]. Because brains have the highest expression of MeCP2, MeCP2 functional deficiency causes neurological diseases such as Rett syndrome [87]. Recent study showed that $\mathrm{MeCP} 2$ was identified as the major $5 \mathrm{hmc}$ binding protein in the brain to facilitate gene expression by organizing the chromatin [88]. Previous study showed a reverse correlation between $\mathrm{MeCP} 2$ and $5 \mathrm{hmC}$ level, suggesting that $\mathrm{MeCP} 2$ binds to $5 \mathrm{mC}$ blocking the conversion of $5 \mathrm{mC}$ to 5hmC [67]. MeCP2 mutations such as R133C (an MeCP2 residue mutated in Rett syndrome) preferentially abolish its binding ability to $5 \mathrm{hmC}$ and account for the role of $5 \mathrm{hmC}$ in the pathophysiology of Rett syndrome, supporting that $5 \mathrm{hmC}$ and MeCP2 constitute an epigenetic regulation complex to control cell differentiation or chromatin structure [88]. Recent studies have shown that $\mathrm{MeCP} 2$ is required for brain development and neuronal differentiation by inhibiting the ID1/Her2 (the zebrafish ortholog of mammalian Hes5) axis in zebrafish because genetic depletion of $\mathrm{MeCP} 2$ inhibited neuronal differentiation but its overexpression promoted neuronal differentiation [89]. However, it is still unclear whether the blocking of $\mathrm{MeCP} 2$ binding to $5 \mathrm{hmC}$ is responsible for neuronal differentiation in Rett syndrome, as awaits more investigations. 


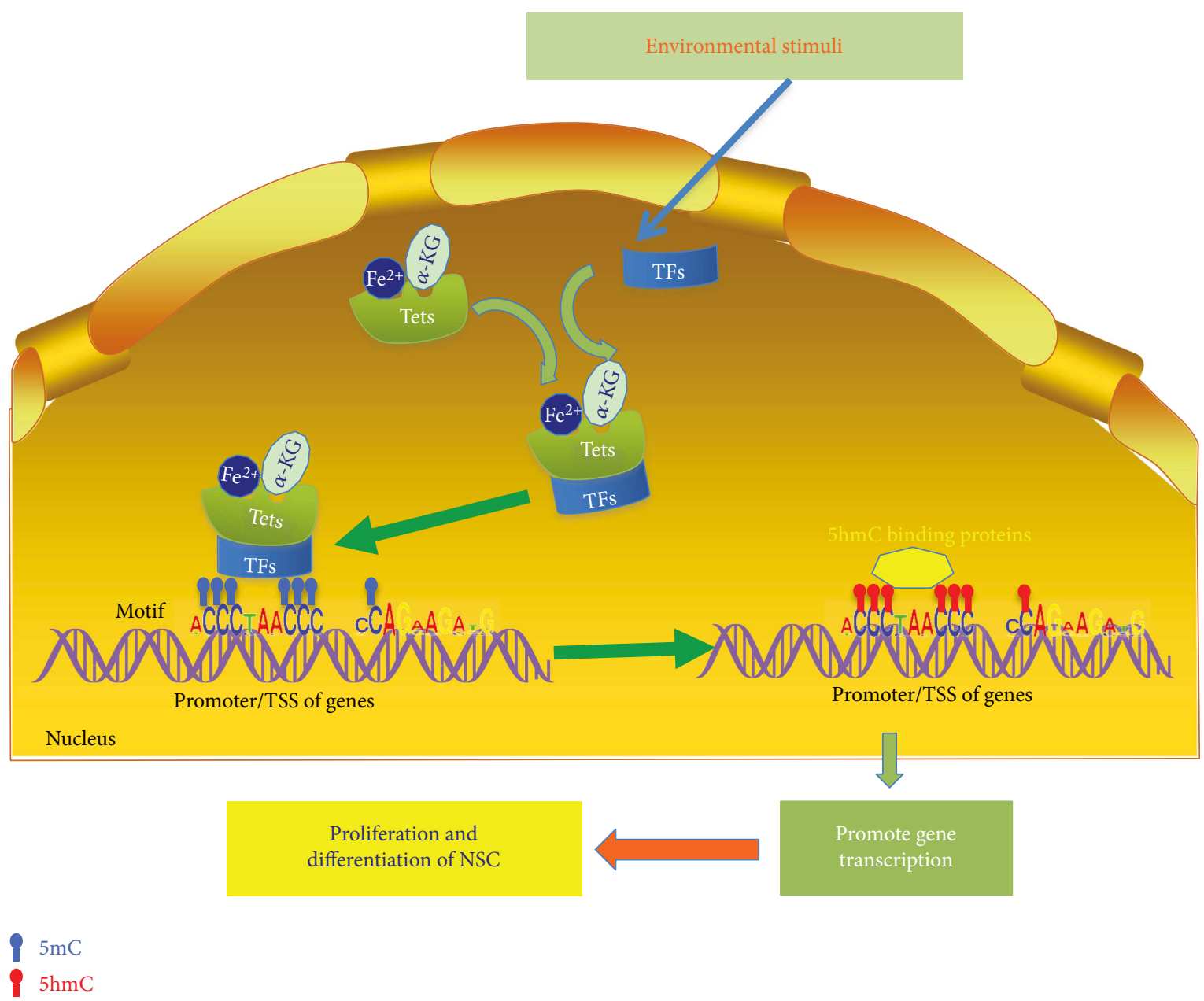

FIGURE 1: Tet proteins and 5-hmC mediated regulation of NSC proliferation and differentiation. Under the conditions of environmental stimuli, some transcriptional factors (TFs) such as FOXO3a enhance the affinity to Tet proteins along with cofactors of Tet enzymes including $\alpha-\mathrm{KG}$ and $\mathrm{Fe}^{2+}$ to form a functional complex. By binding to DNA motifs of the targeting genes, the TFs guide the Tet enzymes to catalyze the conversion of $5 \mathrm{mC}$ to $5 \mathrm{hmC}$. Generation of $5 \mathrm{hmC}$ facilitates the recruitment of the $5 \mathrm{hmC}$ binding proteins or other factors to enhance the transcription of targeting genes, thereby regulating the proliferation and differentiation of NSCs.

5.4. Major Depressive Disorders (MDD). The high morbidity and suicide of depression has become a major health concern in the world [90]. However, the pathogenesis of MDD remains unclear. So far, genetic and environmental factors are considered to interact and participate in the MDD, in which environmental factors mainly affect gene transcription and expression through epigenetic modification. DNA methylation is considered a major epigenetic modification from environmental stress [91]. 5hmC functions as a new DNA demethylation mechanism, however, its role in depressive disorders is unclear. Epigenetic $5 \mathrm{hmC}$ modification, to some extent, provides a possible mechanism for explaining environmental factors that affect gene expression. Recent reports showed that patients with MDD had decreased gray matter volume and white matter integrity in the hippocampus [92]. In addition, Bansal et al. found structural changes in the cerebral cortex of patients with MDD, indicating that thickening of the cerebral cortex is a compensatory nerve growth response [93]. Recent studies have also provided evidence that Tet 1 knockout showed antidepressive phenotypes by affecting neurogenesis in the hippocampus [94]. Therefore, Tet proteins-mediated $5 \mathrm{hmC}$ modifications on depression-related genes are involved the regulation of neurogenesis in the mechanisms of MDD.

\section{Conclusions}

Epigenetic modification is likely to be the collective response to changes in environmental factors as a means of cells or organisms to mitigate the adverse effects [95]. The dynamic changes of methylation $(5 \mathrm{mC})$ and demethylation $(5 \mathrm{hmC})$ in DNA could affect its structure as well as the functions of genes and further lead to different kinds of diseases. Recent advances on $5 \mathrm{hmC}$ modification have demonstrated that Tet proteins and Tet-mediated $5 \mathrm{hmC}$ play important roles in the proliferation and differentiation of NSCs. However, it is unclear how Tet protein, Tet-interacting factors, and DNA $5 \mathrm{hmC}$ in target genes interplay and regulate the devolvement of NSCs. These need more investigations in the future. Recently, DNA N6-Methyldeoxyadenosine $(6 \mathrm{~mA})$ is 
emerging as a new DNA modification and plays an important role in the regulation of the proliferation and differentiation of NSCs [96-98]. The interaction or crosstalking of DNA $5 \mathrm{hmC}$ modification and $6 \mathrm{~mA}$ modification will be an interesting topic. Considering the critical role of neuronal stem cells in the neurological diseases, targeting epigenetic regulation, especially on DNA $5 \mathrm{hmC}$ modification, is a promising strategy for the treatment of these neurological diseases.

\section{Disclosure}

Hang Zhou and Bin Wang are co-first authors.

\section{Conflicts of Interest}

The authors declare that they have no conflicts of interest.

\section{Acknowledgments}

This study was supported by the grants from National Key R\&D Program of China (2017YFE0103700), Natural Science Foundation of Jiangsu Province (BK20141281), Special Foundation Project on the Prospective Study of Social Development in Jiangsu Province (BE2013911), Jiangsu Six Categories of Talent Summit Fund (WSW-133), Social Development of Science and Technology Research Project in Yangzhou (YZ2011082), and Jiangsu Province 333 talent Project (BRA2016159).

\section{References}

[1] L. Bonetta, "Gene expression: an expression of interest," Nature, vol. 440, no. 7088, pp. 1233-1237, 2006.

[2] X. Li and M. G. Rosenfeld, "Transcription: origins of licensing control," Nature, vol. 427, no. 6976, pp. 687-688, 2004.

[3] Z. Shi, K. Fujii, K. M. Kovary et al., "Heterogeneous ribosomes preferentially translate distinct subpools of mRNAs genome-wide," Molecular Cell, vol. 67, no. 1, pp. 71-83.e7, 2017.

[4] S. E. Dwi Putra, C. Reichetzeder, M. Meixner, K. Liere, T. Slowinski, and B. Hocher, "DNA methylation of the glucocorticoid receptor gene promoter in the placenta is associated with blood pressure regulation in human pregnancy," Journal of Hypertension, vol. 35, no. 11, pp. 2276-2286, 2017.

[5] S. Kimmins and P. Sassone-Corsi, "Chromatin remodelling and epigenetic features of germ cells," Nature, vol. 434, no. 7033, pp. 583-589, 2005.

[6] G. I. Evan and K. H. Vousden, "Proliferation, cell cycle and apoptosis in cancer," Nature, vol. 411, no. 6835 , pp. $342-$ 348, 2001.

[7] A. Chhabra, "Derivation of human induced pluripotent stem cell (iPSC) lines and mechanism of pluripotency: historical perspective and recent advances," Stem Cell Reviews and Reports, vol. 13, no. 6, pp. 757-773, 2017.

[8] G. Caocci, M. G. Orofino, A. Vacca et al., "Long-term survival of beta thalassemia major patients treated with hematopoietic stem cell transplantation compared with survival with conventional treatment," American Journal of Hematology, vol. 92, no. 12, pp. 1303-1310, 2017.

[9] B. A. Reynolds and S. Weiss, "Generation of neurons and astrocytes from isolated cells of the adult mammalian central nervous system," Science, vol. 255, no. 5052, pp. 1707-1710, 1992.

[10] S. E. Marsh, S. T. Yeung, M. Torres et al., "HuCNS-SC human NSCs fail to differentiate, form ectopic clusters, and provide no cognitive benefits in a transgenic model of Alzheimer's disease," Stem Cell Reports, vol. 8, no. 2, pp. 235-248, 2017.

[11] Y. H. Rhee, T. H. Kim, A. Y. Jo et al., "LIN28A enhances the therapeutic potential of cultured neural stem cells in a Parkinson's disease model," Brain, vol. 139, no. 10, pp. 2722-2739, 2016.

[12] K. Wiatr, W. J. Szlachcic, M. Trzeciak, M. Figlerowicz, and M. Figiel, "Huntington disease as a neurodevelopmental disorder and early signs of the disease in stem cells," Molecular Neurobiology, pp. 1-21, 2017, inpress.

[13] A. Ramsawhook, L. Lewis, B. Coyle, and A. Ruzov, "Medulloblastoma and ependymoma cells display increased levels of 5-carboxylcytosine and elevated TET1 expression," Clinical Epigenetics, vol. 9, no. 1, 2017.

[14] J. Winkelmann, L. Lin, B. Schormair et al., "Mutations in DNMT1 cause autosomal dominant cerebellar ataxia, deafness and narcolepsy," Human Molecular Genetics, vol. 21, no. 10, pp. 2205-2210, 2012.

[15] L. Q. Cheng, Z. Q. Zhang, H. Z. Chen, and D. P. Liu, "Epigenetic regulation in cell senescence," Journal of Molecular Medicine, vol. 95, no. 12, pp. 1257-1268, 2017.

[16] Y. C. Sun, Y. Y. Wang, W. Ge, S. F. Cheng, P. W. Dyce, and W. Shen, "Epigenetic regulation during the differentiation of stem cells to germ cells," Oncotarget, vol. 8, no. 34, pp. 57836-57844, 2017.

[17] L. Luo, W. J. Chen, J. Q. Yin, and R. X. Xu, "EID3 directly associates with DNMT3A during transdifferentiation of human umbilical cord mesenchymal stem cells to NPC-like cells," Scientific Reports, vol. 7, article 40463, 2017.

[18] W. Feng, M. A. Khan, P. Bellvis et al., "The chromatin remodeler CHD7 regulates adult neurogenesis via activation of SoxC transcription factors," Cell Stem Cell, vol. 13, no. 1, pp. 62-72, 2013.

[19] M. Strigini and F. Leulier, "The role of the microbial environment in drosophila post-embryonic development," Developmental and Comparative Immunology, vol. 64, pp. 39-52, 2016.

[20] N. Kuzumaki, D. Ikegami, R. Tamura et al., "Hippocampal epigenetic modification at the brain-derived neurotrophic factor gene induced by an enriched environment," Hippocampus, vol. 21, no. 2, pp. 127-132, 2011.

[21] F. Zenk, E. Loeser, R. Schiavo, F. Kilpert, O. Bogdanovic, and $\mathrm{N}$. Iovino, "Germ line-inherited $\mathrm{H} 3 \mathrm{~K} 27 \mathrm{me} 3$ restricts enhancer function during maternal-to-zygotic transition," Science, vol. 357, no. 6347, pp. 212-216, 2017.

[22] G. A. Challen, D. Sun, M. Jeong et al., "Dnmt3a is essential for hematopoietic stem cell differentiation," Nature Genetics, vol. 44, no. 1, pp. 23-31, 2011.

[23] N. S. Christophersen and K. Helin, "Epigenetic control of embryonic stem cell fate," The Journal of Experimental Medicine, vol. 207, no. 11, pp. 2287-2295, 2010.

[24] M. Kaneda, M. Okano, K. Hata et al., "Essential role for de novo DNA methyltransferase Dnmt3a in paternal and maternal imprinting," Nature, vol. 429, no. 6994, pp. 900-903, 2004.

[25] Y. Cai, H. C. Tsai, R. C. Yen et al., "Critical threshold levels of DNA methyltransferase 1 are required to maintain DNA 
methylation across the genome in human cancer cells," Genome Research, vol. 27, no. 4, pp. 533-544, 2017.

[26] R. C. Laker and J. G. Ryall, "DNA methylation in skeletal muscle stem cell specification, proliferation, and differentiation," Stem Cells International, vol. 2016, Article ID 5725927, 9 pages, 2016.

[27] V. Ramesh, E. Bayam, F. M. Cernilogar et al., "Loss of Uhrf1 in neural stem cells leads to activation of retroviral elements and delayed neurodegeneration," Genes \& Development, vol. 30, no. 19, pp. 2199-2212, 2016.

[28] E. M. Jobe, Y. Gao, B. E. Eisinger et al., "Methyl-CpGbinding protein MBD1 regulates neuronal lineage commitment through maintaining adult neural stem cell identity," The Journal of Neuroscience, vol. 37, no. 3, pp. 523-536, 2017.

[29] V. R. Liyanage, R. M. Zachariah, J. R. Davie, and M. Rastegar, "Ethanol deregulates Mecp2/MeCP2 in differentiating neural stem cells via interplay between 5-methylcytosine and 5hydroxymethylcytosine at the Mecp2 regulatory elements," Experimental Neurology, vol. 265, pp. 102-117, 2015.

[30] S. F. Chaudry and T. J. Chevassut, "Epigenetic Guardian: a review of the DNA methyltransferase DNMT3A in acute myeloid Leukaemia and clonal Haematopoiesis," BioMed Research International, vol. 2017, Article ID 5473197, 13 pages, 2017.

[31] F. C. Zhou, Y. Balaraman, M. Teng, Y. Liu, R. P. Singh, and K. P. Nephew, "Alcohol alters DNA methylation patterns and inhibits neural stem cell differentiation," Alcoholism, Clinical and Experimental Research, vol. 35, no. 4, pp. 735746, 2011.

[32] B. Srinageshwar, P. Maiti, G. L. Dunbar, and J. Rossignol, "Role of epigenetics in stem cell proliferation and differentiation: implications for treating neurodegenerative diseases," International Journal of Molecular Sciences, vol. 17, no. 2, p. 199, 2016.

[33] S. B. Foti, A. Chou, A. D. Moll, and A. J. Roskams, "HDAC inhibitors dysregulate neural stem cell activity in the postnatal mouse brain," International Journal of Developmental Neuroscience, vol. 31, no. 6, pp. 434-447, 2013.

[34] R. Soriano-Canton, A. Perez-Villalba, J. M. Morante-Redolat et al., "Regulation of the p19(Arf)/p53 pathway by histone acetylation underlies neural stem cell behavior in senescenceprone SAMP8 mice," Aging Cell, vol. 14, no. 3, pp. 453-462, 2015.

[35] G. Sun, K. Alzayady, R. Stewart et al., "Histone demethylase LSD1 regulates neural stem cell proliferation," Molecular and Cellular Biology, vol. 30, no. 8, pp. 1997-2005, 2010.

[36] A. Adamo, B. Sese, S. Boue et al., "LSD1 regulates the balance between self-renewal and differentiation in human embryonic stem cells," Nature Cell Biology, vol. 13, no. 6, pp. 652659, 2011.

[37] S. Bian and T. Sun, "Functions of noncoding RNAs in neural development and neurological diseases," Molecular Neurobiology, vol. 44, no. 3, pp. 359-373, 2011.

[38] F. Gao, Y. F. Zhang, Z. P. Zhang et al., "miR-342-5p regulates neural stem cell proliferation and differentiation downstream to notch signaling in mice," Stem Cell Reports, vol. 8, no. 4, pp. 1032-1045, 2017.

[39] M. A. Lopez-Ramirez and S. Nicoli, "Role of miRNAs and epigenetics in neural stem cell fate determination," Epigenetics, vol. 9, no. 1, pp. 90-100, 2014.
[40] A. L. Morgado, C. M. Rodrigues, and S. Sola, "MicroRNA145 regulates neural stem cell differentiation through the Sox2-Lin28/let-7 signaling pathway," Stem Cells, vol. 34, no. 5, pp. 1386-1395, 2016.

[41] C. Liu, Z. Q. Teng, N. J. Santistevan et al., "Epigenetic regulation of miR-184 by MBD1 governs neural stem cell proliferation and differentiation," Cell Stem Cell, vol. 6, no. 5, pp. 433-444, 2010.

[42] W. Yan, Z. Y. Chen, J. Q. Chen, and H. M. Chen, "BMP2 promotes the differentiation of neural stem cells into dopaminergic neurons in vitro via miR-145-mediated upregulation of Nurr1 expression," American Journal of Translational Research, vol. 8, no. 9, pp. 3689-3699, 2016.

[43] N. Xu, T. Papagiannakopoulos, G. Pan, J. A. Thomson, and K. S. Kosik, "MicroRNA-145 regulates OCT4, SOX2, and KLF4 and represses pluripotency in human embryonic stem cells," Cell, vol. 137, no. 4, pp. 647-658, 2009.

[44] Y. Zhang, M. S. Kim, B. Jia et al., "Hypothalamic stem cells control ageing speed partly through exosomal miRNAs," Nature, vol. 548, no. 7665, pp. 52-57, 2017.

[45] X. Wu and Y. Zhang, "TET-mediated active DNA demethylation: mechanism, function and beyond," Nature Reviews. Genetics, vol. 18, no. 9, pp. 517-534, 2017.

[46] M. Tahiliani, K. P. Koh, Y. Shen et al., "Conversion of 5methylcytosine to 5-hydroxymethylcytosine in mammalian DNA by MLL partner TET1," Science, vol. 324, no. 5929, pp. 930-935, 2009.

[47] S. Ito, A. C. D'Alessio, O. V. Taranova, K. Hong, L. C. Sowers, and Y. Zhang, "Role of Tet proteins in $5 \mathrm{mC}$ to $5 \mathrm{hmC}$ conversion, ES-cell self-renewal and inner cell mass specification," Nature, vol. 466, no. 7310, pp. 1129-1133, 2010.

[48] K. P. Koh, A. Yabuuchi, S. Rao et al., "Tet1 and Tet2 regulate 5-hydroxymethylcytosine production and cell lineage specification in mouse embryonic stem cells," Cell Stem Cell, vol. 8, no. 2, pp. 200-213, 2011.

[49] K. Williams, J. Christensen, M. T. Pedersen et al., "TET1 and hydroxymethylcytosine in transcription and DNA methylation fidelity," Nature, vol. 473, no. 7347, pp. 343348, 2011.

[50] Y. Xu, F. Wu, L. Tan et al., "Genome-wide regulation of $5 \mathrm{hmC}, 5 \mathrm{mC}$, and gene expression by Tet1 hydroxylase in mouse embryonic stem cells," Molecular Cell, vol. 42, no. 4, pp. 451-464, 2011.

[51] T. P. Gu, F. Guo, H. Yang et al., "The role of Tet3 DNA dioxygenase in epigenetic reprogramming by oocytes," Nature, vol. 477, no. 7366, pp. 606-610, 2011.

[52] M. Ko, J. An, H. S. Bandukwala et al., "Modulation of TET2 expression and 5-methylcytosine oxidation by the CXXC domain protein IDAX," Nature, vol. 497, no. 7447, pp. 122126, 2013.

[53] S. Hino, S. Kishida, T. Michiue et al., "Inhibition of the Wnt signaling pathway by Idax, a novel Dvl-binding protein," Molecular and Cellular Biology, vol. 21, no. 1, pp. 330-342, 2001.

[54] S. Knappskog, L. M. Myklebust, C. Busch et al., "RINF (CXXC5) is overexpressed in solid tumors and is an unfavorable prognostic factor in breast cancer," Annals of Oncology, vol. 22, no. 10, pp. 2208-2215, 2011.

[55] R. R. Zhang, Q. Y. Cui, K. Murai et al., "Tet1 regulates adult hippocampal neurogenesis and cognition," Cell Stem Cell, vol. 13 , no. 2, pp. $237-245,2013$. 
[56] K. Moran-Crusio, L. Reavie, A. Shih et al., "Tet2 loss leads to increased hematopoietic stem cell self-renewal and myeloid transformation," Cancer Cell, vol. 20, no. 1, pp. 11-24, 2011.

[57] S. Kriaucionis and N. Heintz, "The nuclear DNA base 5hydroxymethylcytosine is present in Purkinje neurons and the brain," Science, vol. 324, no. 5929, pp. 929-930, 2009.

[58] X. Li, B. Yao, L. Chen et al., "Ten-eleven translocation 2 interacts with forkhead box $\mathrm{O} 3$ and regulates adult neurogenesis," Nature Communications, vol. 8, article 15903, 2017.

[59] L. M. Wheldon, A. Abakir, Z. Ferjentsik et al., "Transient accumulation of 5-carboxylcytosine indicates involvement of active demethylation in lineage specification of neural stem cells," Cell Reports, vol. 7, no. 5, pp. 1353-1361, 2014.

[60] L. C. Lewis, P. C. Lo, J. M. Foster et al., "Dynamics of 5-carboxylcytosine during hepatic differentiation: potential general role for active demethylation by DNA repair in lineage specification," Epigenetics, vol. 12, no. 4, pp. 277-286, 2017.

[61] S. Ito, L. Shen, Q. Dai et al., "Tet proteins can convert 5methylcytosine to 5-formylcytosine and 5-carboxylcytosine," Science, vol. 333, no. 6047, pp. 1300-1303, 2011.

[62] B. E. Bernstein, A. Meissner, and E. S. Lander, "The mammalian epigenome," Cell, vol. 128, no. 4, pp. 669-681, 2007.

[63] M. Bibikova, L. C. Laurent, B. Ren, J. F. Loring, and J. B. Fan, "Unraveling epigenetic regulation in embryonic stem cells," Cell Stem Cell, vol. 2, no. 2, pp. 123-134, 2008.

[64] D. Thomas and M. Kansara, "Epigenetic modifications in osteogenic differentiation and transformation," Journal of Cellular Biochemistry, vol. 98, no. 4, pp. 757-769, 2006.

[65] S. Barrand and P. Collas, "Chromatin states of core pluripotency-associated genes in pluripotent, multipotent and differentiated cells," Biochemical and Biophysical Research Communications, vol. 391, no. 1, pp. 762-767, 2010.

[66] N. Ballas, C. Grunseich, D. D. Lu, J. C. Speh, and G. Mandel, "REST and its corepressors mediate plasticity of neuronal gene chromatin throughout neurogenesis," Cell, vol. 121, no. 4, pp. 645-657, 2005.

[67] K. E. Szulwach, X. Li, Y. Li et al., "5-hmC-mediated epigenetic dynamics during postnatal neurodevelopment and aging," Nature Neuroscience, vol. 14, no. 12, pp. 1607-1616, 2011.

[68] J. P. Etchegaray, L. Chavez, Y. Huang et al., "The histone deacetylase SIRT6 controls embryonic stem cell fate via TETmediated production of 5-hydroxymethylcytosine," Nature Cell Biology, vol. 17, no. 5, pp. 545-557, 2015.

[69] M. A. Hahn, R. Qiu, X. Wu et al., "Dynamics of 5hydroxymethylcytosine and chromatin marks in mammalian neurogenesis," Cell Reports, vol. 3, no. 2, pp. 291-300, 2013.

[70] S. Hannenhalli and K. H. Kaestner, "The evolution of Fox genes and their role in development and disease," Nature Reviews Genetics, vol. 10, no. 4, pp. 233-240, 2009.

[71] R. Bose, S. Spulber, P. Kilian et al., "Tet3 mediates stable glucocorticoid-induced alterations in DNA methylation and Dnmt3a/Dkk1 expression in neural progenitors," Cell Death \& Disease, vol. 6, no. 6, article e1793, 2015.

[72] T. Li, D. Yang, J. Li, Y. Tang, J. Yang, and W. Le, "Critical role of Tet3 in neural progenitor cell maintenance and terminal differentiation," Molecular Neurobiology, vol. 51, no. 1, pp. 142-154, 2015.

[73] A. Iatrou, G. Kenis, B. P. Rutten, K. Lunnon, and D. L. van den Hove, "Epigenetic dysregulation of brainstem nuclei in the pathogenesis of Alzheimer's disease: looking in the correct place at the right time?," Cellular and Molecular Life Sciences, vol. 74, no. 3, pp. 509-523, 2017.

[74] S. W. Bihaqi, A. Schumacher, B. Maloney, D. K. Lahiri, and N. H. Zawia, "Do epigenetic pathways initiate late onset Alzheimer disease (LOAD): towards a new paradigm," Current Alzheimer Research, vol. 9, no. 5, pp. 574-588, 2012.

[75] L. Chouliaras, D. Mastroeni, E. Delvaux et al., "Consistent decrease in global DNA methylation and hydroxymethylation in the hippocampus of Alzheimer's disease patients," Neurobiology of Aging, vol. 34, no. 9, pp. 2091-2099, 2013.

[76] J. S. Rao, V. L. Keleshian, S. Klein, and S. I. Rapoport, “Epigenetic modifications in frontal cortex from Alzheimer's disease and bipolar disorder patients," Translational Psychiatry, vol. 2, no. 7, article e132, 2012.

[77] L. Shu, W. Sun, L. Li et al., "Genome-wide alteration of 5-hydroxymenthylcytosine in a mouse model of Alzheimer's disease," BMC Genomics, vol. 17, no. 1, 2016.

[78] A. I. Bernstein, Y. Lin, R. C. Street et al., "5-Hydroxymethylation-associated epigenetic modifiers of Alzheimer's disease modulate Tau-induced neurotoxicity," Human Molecular Genetics, vol. 25, no. 12, pp. 2437-2450, 2016.

[79] M. A. Bradley-Whitman and M. A. Lovell, "Epigenetic changes in the progression of Alzheimer's disease," Mechanisms of Ageing and Development, vol. 134, no. 10, pp. 486495, 2013.

[80] A. Rudenko, M. M. Dawlaty, J. Seo et al., "Tet1 is critical for neuronal activity-regulated gene expression and memory extinction," Neuron, vol. 79, no. 6, pp. 1109-1122, 2013.

[81] S. Horvath, P. Langfelder, S. Kwak et al., "Huntington's disease accelerates epigenetic aging of human brain and disrupts DNA methylation levels," Aging, vol. 8, no. 7, pp. 1485-1512, 2016.

[82] F. Wang, Y. Yang, X. Lin et al., "Genome-wide loss of 5-hmC is a novel epigenetic feature of Huntington's disease," Human Molecular Genetics, vol. 22, no. 18, pp. 3641-3653, 2013.

[83] I. Villar-Menendez, M. Blanch, S. Tyebji et al., "Increased 5-methylcytosine and decreased 5-hydroxymethylcytosine levels are associated with reduced striatal A2AR levels in Huntington's disease," Neuromolecular Medicine, vol. 15, no. 2, pp. 295-309, 2013.

[84] B. Winner, Z. Kohl, and F. H. Gage, "Neurodegenerative disease and adult neurogenesis," The European Journal of Neuroscience, vol. 33, no. 6, pp. 1139-1151, 2011.

[85] M. Vashishtha, C. W. Ng, F. Yildirim et al., "Targeting H3K4 trimethylation in Huntington disease," Proceedings of the National Academy of Sciences of the United States of America, vol. 110, no. 32, pp. E3027-E3036, 2013.

[86] R. E. Amir, I. B. Van den Veyver, M. Wan, C. Q. Tran, U. Francke, and H. Y. Zoghbi, "Rett syndrome is caused by mutations in X-linked MECP2, encoding methyl-CpGbinding protein 2," Nature Genetics, vol. 23, no. 2, pp. 185$188,1999$.

[87] M. D. Shahbazian, B. Antalffy, D. L. Armstrong, and H. Y. Zoghbi, "Insight into Rett syndrome: MeCP2 levels display tissue- and cell-specific differences and correlate with neuronal maturation," Human Molecular Genetics, vol. 11, no. 2, pp. 115-124, 2002.

[88] M. Mellen, P. Ayata, S. Dewell, S. Kriaucionis, and N. Heintz, "MeCP2 binds to $5 \mathrm{hmC}$ enriched within active genes and accessible chromatin in the nervous system," Cell, vol. 151, no. 7, pp. 1417-1430, 2012. 
[89] H. Gao, Y. Bu, Q. Wu et al., "Mecp2 regulates neural cell differentiation by suppressing the Id1 to Her2 axis in zebrafish," Journal of Cell Science, vol. 128, no. 12, pp. 2340-2350, 2015.

[90] K. Smith, "Mental health: a world of depression," Nature, vol. 515, no. 7526, p. 181, 2014.

[91] E. Pishva, B. P. F. Rutten, and D. van den Hove, "DNA methylation in major depressive disorder," Advances in Experimental Medicine and Biology, vol. 978, pp. 185-196, 2017.

[92] X. Shen, L. M. Reus, S. R. Cox et al., "Subcortical volume and white matter integrity abnormalities in major depressive disorder: findings from UK Biobank imaging data," Scientific Reports, vol. 7, no. 1, p. 5547, 2017.

[93] R. Bansal, D. J. Hellerstein, and B. S. Peterson, "Evidence for neuroplastic compensation in the cerebral cortex of persons with depressive illness," Molecular Psychiatry, vol. 23, no. 2, pp. 375-383, 2018.

[94] J. Feng, C. J. Pena, I. Purushothaman et al., "Tet1 in nucleus accumbens opposes depression- and anxiety-like behaviors," Neuropsychopharmacology, vol. 42, no. 8, pp. 1657-1669, 2017.

[95] M. Munzel, D. Globisch, and T. Carell, "5-Hydroxymethylcytosine, the sixth base of the genome," Angewandte Chemie (International Ed. in English), vol. 50, no. 29, pp. 64606468, 2011.

[96] Y. Fu, G. Z. Luo, K. Chen et al., "N6-methyldeoxyadenosine marks active transcription start sites in Chlamydomonas," Cell, vol. 161, no. 4, pp. 879-892, 2015.

[97] B. Yao, Y. Cheng, Z. Wang et al., "DNA N6-methyladenine is dynamically regulated in the mouse brain following environmental stress," Nature Communications, vol. 8, no. 1, p. 1122, 2017.

[98] K. J. Yoon, F. R. Ringeling, C. Vissers et al., “Temporal control of mammalian cortical neurogenesis by $\mathrm{m}^{6} \mathrm{~A}$ methylation," Cell, vol. 171, no. 4, pp. 877-889.e17, 2017.

[99] M. M. Dawlaty, K. Ganz, B. E. Powell et al., "Tet1 is dispensable for maintaining pluripotency and its loss is compatible with embryonic and postnatal development," Cell Stem Cell, vol. 9, no. 2, pp. 166-175, 2011.

[100] X. Jiang, C. Hu, K. Ferchen et al., "Targeted inhibition of STAT/TET1 axis as a therapeutic strategy for acute myeloid leukemia," Nature Communications, vol. 8, no. 1, p. 2099, 2017.

[101] H. L. Fu, Y. Ma, L. G. Lu et al., "TET1 exerts its tumor suppressor function by interacting with p53-EZH2 pathway in gastric cancer," Journal of Biomedical Nanotechnology, vol. 10, no. 7, pp. 1217-1230, 2014.

[102] Q. Yang, K. Wu, M. Ji et al., "Decreased 5hydroxymethylcytosine $(5-\mathrm{hmC})$ is an independent poor prognostic factor in gastric cancer patients," Journal of Biomedical Nanotechnology, vol. 9, no. 9, pp. 1607-1616, 2013.

[103] M. Deng, R. Zhang, Z. He et al., "TET-mediated sequestration of miR-26 drives EZH2 expression and gastric carcinogenesis," Cancer Research, vol. 77, no. 22, pp. 6069-6082, 2017.

[104] M. Sun, C. X. Song, H. Huang et al., "HMGA2/TET1/ HOXA9 signaling pathway regulates breast cancer growth and metastasis," Proceedings of the National Academy of Sciences of the United States of America, vol. 110, no. 24, pp. 9920-9925, 2013.

[105] P. Seritrakul and J. M. Gross, "Tet-mediated DNA hydroxymethylation regulates retinal neurogenesis by modulating cell-extrinsic signaling pathways," PLoS Genetics, vol. 13, no. 9, article e1006987, 2017.

[106] J. S. Ha, D. S. Jeon, J. R. Kim, N. H. Ryoo, and J. S. Suh, “Analysis of the Ten-Eleven Translocation 2 (TET2) gene mutation in myeloproliferative neoplasms," Annals of Clinical and Laboratory Science, vol. 44, no. 2, pp. 173-179, 2014.

[107] P. Jain, S. Verstovsek, W. Wang et al., "DNMT3A, TET2, and JAK2 mutations in polycythemia vera following long-term remission of secondary acute myeloid leukemia," Leukemia \& Lymphoma, vol. 57, no. 8, pp. 1969-1973, 2016.

[108] E. Chen, R. K. Schneider, L. J. Breyfogle et al., "Distinct effects of concomitant Jak2V617F expression and Tet2 loss in mice promote disease progression in myeloproliferative neoplasms," Blood, vol. 125, no. 2, pp. 327-335, 2015.

[109] C. G. Lian, Y. Xu, C. Ceol et al., "Loss of 5hydroxymethylcytosine is an epigenetic hallmark of melanoma," Cell, vol. 150, no. 6, pp. 1135-1146, 2012.

[110] A. Inoue, L. Shen, S. Matoba, and Y. Zhang, "Haploinsufficiency, but not defective paternal $5 \mathrm{mC}$ oxidation, accounts for the developmental defects of maternal Tet3 knockouts," Cell Reports, vol. 10, no. 4, pp. 463-470, 2015.

[111] X. Li, W. Wei, Q. Y. Zhao et al., "Neocortical Tet3-mediated accumulation of 5-hydroxymethylcytosine promotes rapid behavioral adaptation," Proceedings of the National Academy of Sciences of the United States of America, vol. 111, no. 19, pp. 7120-7125, 2014.

[112] X. Li, X. Yue, W. A. Pastor et al., “Tet proteins influence the balance between neuroectodermal and mesodermal fate choice by inhibiting Wnt signaling," Proceedings of the National Academy of Sciences of the United States of America, vol. 113, no. 51, pp. E8267-E8276, 2016.

[113] M. M. Dawlaty, A. Breiling, T. Le et al., "Combined deficiency of Tet 1 and Tet 2 causes epigenetic abnormalities but is compatible with postnatal development," Developmental Cell, vol. 24, no. 3, pp. 310-323, 2013.

[114] X. Zhu, D. Girardo, E. E. Govek et al., "Role of Tet1/3 genes and chromatin remodeling genes in cerebellar circuit formation," Neuron, vol. 89, no. 1, pp. 100-112, 2016.

[115] J. Kang, M. Lienhard, W. A. Pastor et al., "Simultaneous deletion of the methylcytosine oxidases Tet1 and Tet3 increases transcriptome variability in early embryogenesis," Proceedings of the National Academy of Sciences of the United States of America, vol. 112, no. 31, pp. E4236-E4245, 2015.

[116] H. Q. Dai, B. A. Wang, L. Yang et al., “TET-mediated DNA demethylation controls gastrulation by regulating LeftyNodal signalling," Nature, vol. 538, no. 7626, pp. 528-532, 2016. 


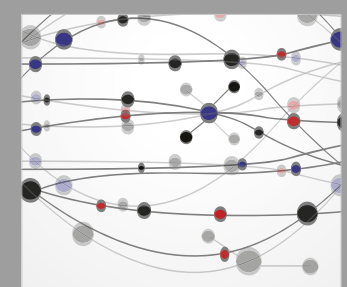

The Scientific World Journal
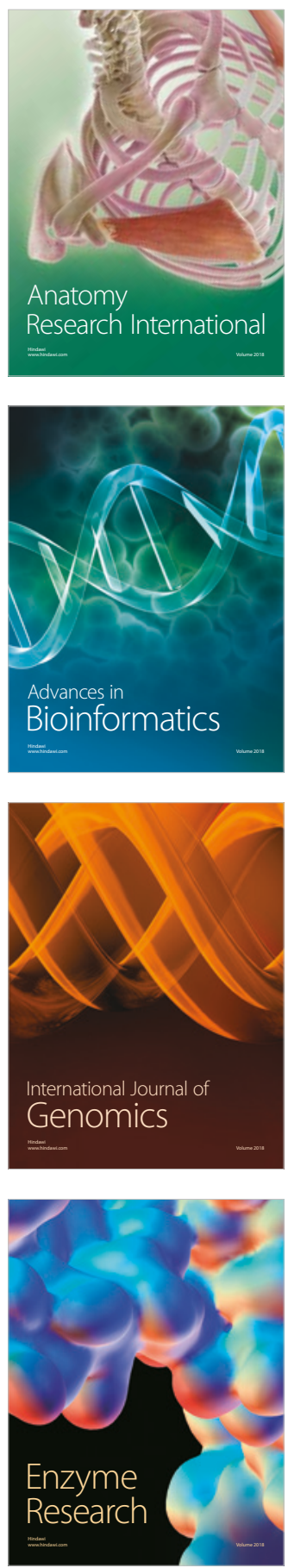
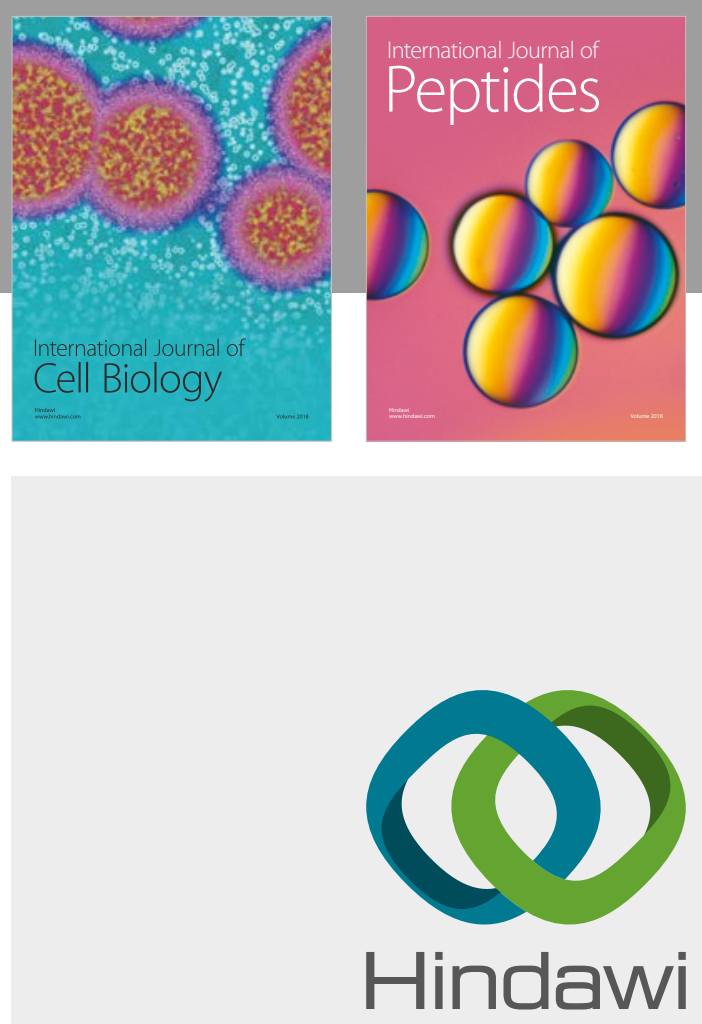

Submit your manuscripts at

www.hindawi.com
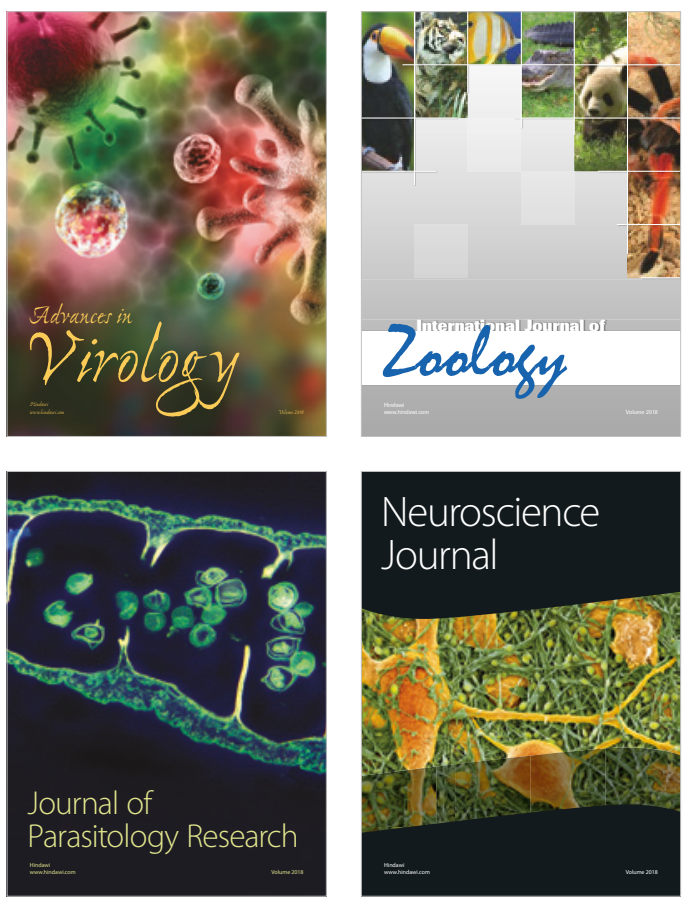
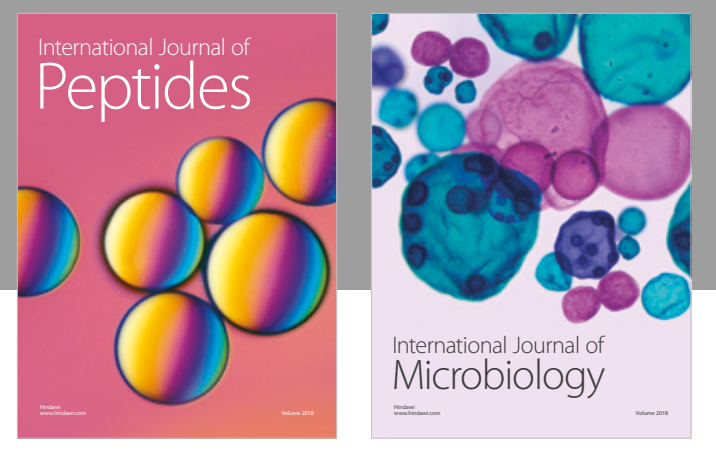

nternational Journal of Microbiology
Journal of
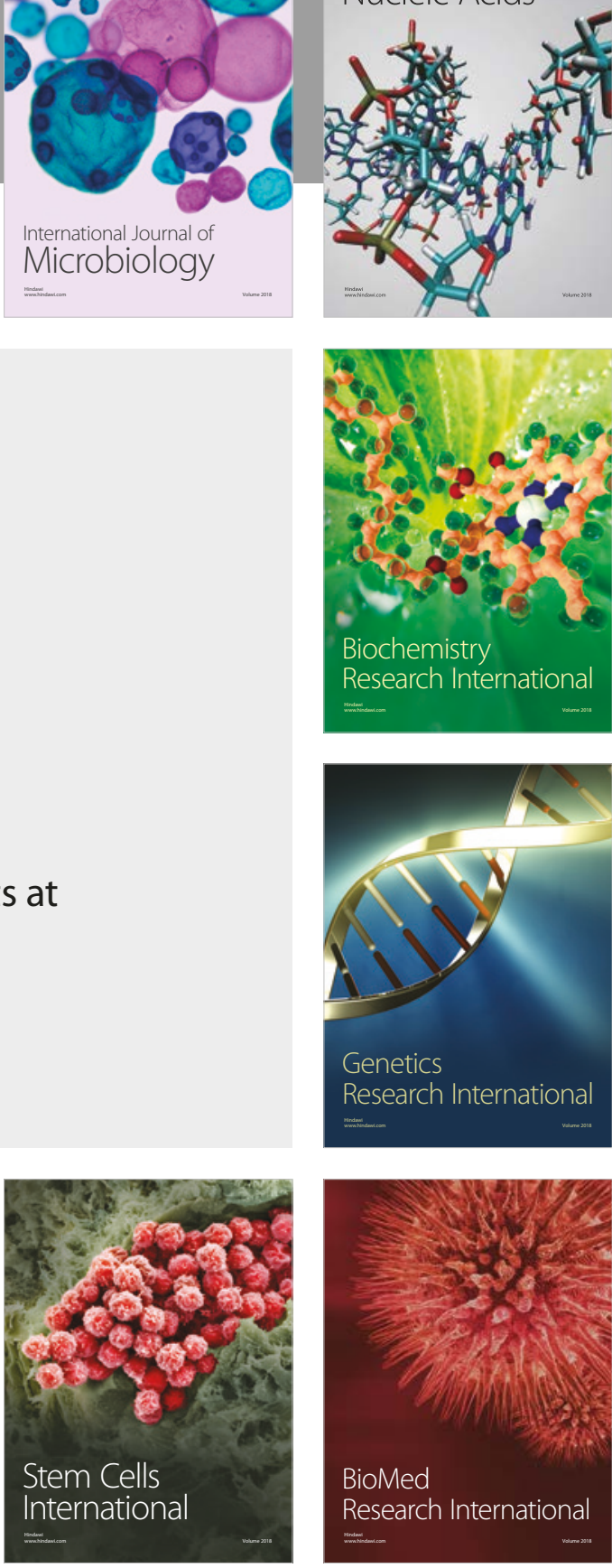
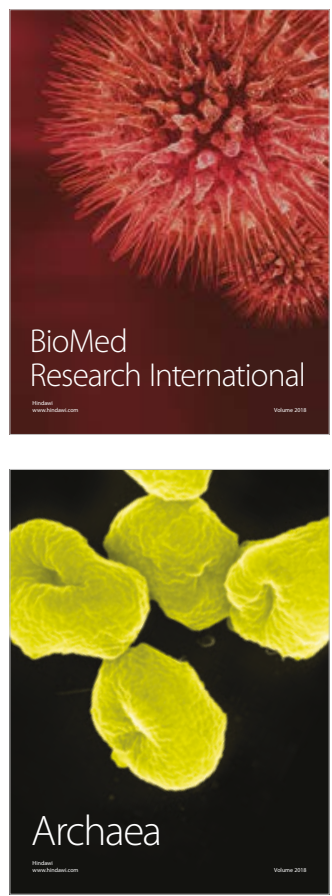